\title{
Synthesis and Evaluation of CQC-1-An Oil Field Scale Inhibitor
}

\author{
Qichao Cao, Xintong Li, Xiong Wang, Song Wang* \\ Yangtze University, Jingzhou, China \\ Email: 1096448904@qq.com, *1508871707@qq.com
}

How to cite this paper: Cao, Q.C., Li, X.T., Wang, X. and Wang, S. (2022) Synthesis and Evaluation of CQC-1-An Oil Field Scale Inhibitor. Open Journal of Yangtze Gas and Oil, 7, 13-25.

https://doi.org/10.4236/ojogas.2022.71002

Received: November 17, 2021

Accepted: December 26, 2021

Published: December 29, 2021

Copyright $\odot 2022$ by author(s) and Scientific Research Publishing Inc. This work is licensed under the Creative Commons Attribution International License (CC BY 4.0).

http://creativecommons.org/licenses/by/4.0/ (c) (i) Open Access

\begin{abstract}
Most of the oil wells enter the middle and late stages of extraction. After one oil extraction, water injection is needed for secondary extraction. With a large amount of calcium and magnesium ions in the water, which is easy to form a large amount of insoluble scale, its formed barium sulfate and strontium sulfate scale are more difficult to handle than carbonate scale. In order to reduce the difficulty of oil production work, this paper mainly targeted the sulfate scale for experiments, and prepared the scale retardant agent CQC-1. Through orthogonal experimental screening, the mass ratio of itaconate acid:methacrylic acid:AMPS:sodium acrylic sulfonate was 2:1:1:1, increase the amount of evocating agent was $8 \%$ and the reaction time was $4 \mathrm{~h}$, the sulfate scale inhibitor synthesized at the temperature of $80^{\circ} \mathrm{C}$ had the best performance. Using scale resistance rate, degradation and salt-resistance, the experimental results showed that the scale resistance rate of CQC-1 reached $90.46 \%$. In the four-week degradation experiment, the degradation rate reached over $71 \%$ and was maintained by $80.65 \%$ at $150^{\circ} \mathrm{C}$, while the scale resistance rate still reached $80.35 \%$ in simulated saline. It has excellent scale resistance, temperature resistance, saltresistance and degradation, and has good development prospects.
\end{abstract}

\section{Keywords}

Scale Resistance Agent, Synthetic Monomer, Synthetic Conditions, Performance Evaluation, Scale Resistance Rate

\section{Introduction}

Nowadays, the oil production work in China has been carried out in the middle and late stages, leading to the change of mining mode and efficiency. However, in order to ensure enough pressure of oil production and the recovery of crude oil, most oil fields began to adopt water injection pressurized oil production [1] [2]. With the increasing degree of oilfield development, the difficulty of water 
injection and development is also gradually increased. At the same time, with the strengthening of the national and people's environmental awareness, the oilfield return water injection is treated and discharged after reaching the national standards, which is one of the important factors for oilfield oil production to achieve high efficiency, high efficiency and high environmental protection operation [3]. Found by Chinese scholars, the sewage composition produced in the oil field is complex, easy to scale ions, such as $\mathrm{Ca}^{2+}, \mathrm{Mg}^{2+}$ ions, $\mathrm{Ba}^{2+}, \mathrm{Sr}^{2+}$ ions, $\mathrm{SO}_{4}^{2-}, \mathrm{CO}_{3}^{2-}$, etc [4] [5]. A large number of scale ions brings great challenges to the normal production of the oil field. When the sewage is extracted for reinjection, these scaling ions are very easily separated in the inner wall of the pipeline due to the changes in temperature, $\mathrm{PH}$ and other conditions. At the same time, their scaling speed is very fast and can cause the pipe drag to rise or block the pipe. What's more, because the scale layer is not evenly covered on the metal surface, the pipe pipeline is exposed, thus causing serious local corrosion or spot corrosion perforation, which seriously endangering the normal operation of the pipeline [6] [7] [8]. Therefore, how to prevent scale, how to remove these generated calcium scale and barium strontium scale has become a hot topic of research.

\section{Experimental Section}

\subsection{The Experimental Materials}

\section{The main chemical experiment}

Itaconic acid, sodium allyl sulfonic acid, methyl acrylate, allyl sulfonate, AMPS, Barium sulfate, strontium sulfate are analytically pure. Hydrogen peroxide, ammonium persulfate and potassium persulfate are as initiator.

\section{The main experimental instrument}

The HH type number shows the constant temperature water bath pot, electronic balance, DF-101s collection hot type constant temperature heating magnetic stirrer, $\mathrm{pH}$ paper, thermostatic drum wind drying oven.

\subsection{A Device for the Biosynthesis}

A schematic diagram of the synthesis device is shown in Figure 1.

\subsection{Methods of Synthetic Experiments}

The synthetic experimental method in this paper is using aqueous solution polymerization method [9] [10]. The step is: fully dissolve a certain ratio of solid monomer in distilled water, and then add liquid monomer. When the temperature of the water bath rises to the predetermined temperature, open the mixer and spin on the constant pressure drop pump valve for the initiator, and the polymerization begins in the system. After the addition of the initiator drop, continue to stir at the predetermined temperature for a certain time to give sufficient reaction time for the monomer polymerization reaction. Wait until a certain amount of time to take out three flasks and place them in the laboratory to cool them, to get a transparent and slightly viscous liquid. 


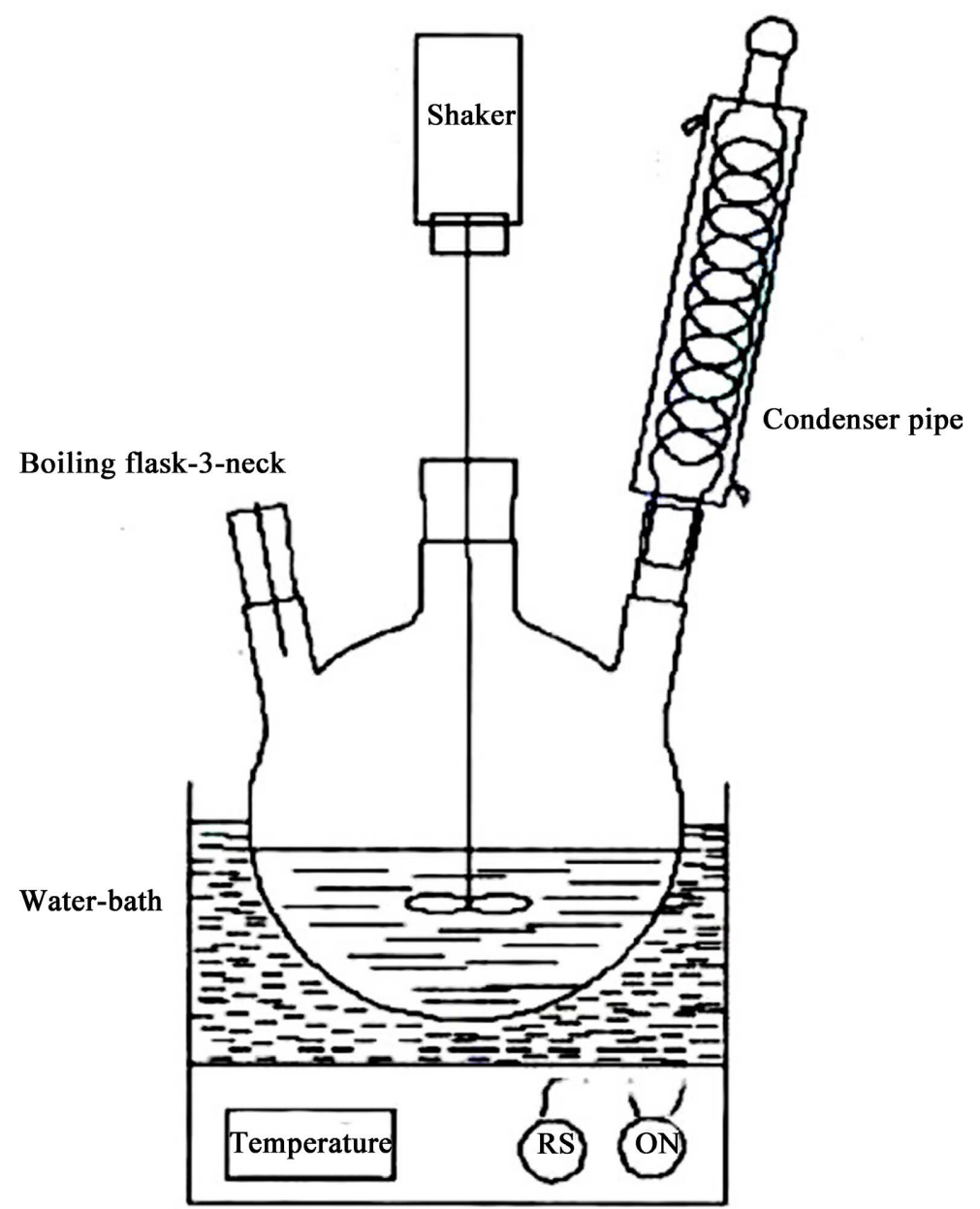

Figure 1. Schematic diagram of the scale inhibitor synthesis device.

\subsection{Evaluation Method of Scale Resistance Rate}

This paper is evaluated using the static scale resistance method [11]. The principle is: prepare a certain volume, concentration of hard water test solution containing $\mathrm{Ca}^{2+}$ and $\mathrm{Mg}^{2+}$, add the appropriate concentration of carbonate or sulfate, under certain temperature and $\mathrm{pH}$ conditions, after $\mathrm{CaCO}_{3}$ or $\mathrm{CaSO}_{4}$ precipitation is fully equilibrium, the remaining hardness in the upper clearing night or filtrate is determined by EDTA solution to obtain the blank test value. For the test solution of the same composition, a certain amount of scale inhibitor shall be added, and the residual hardness of the supernatant or filter is determined by the same method, and the correlation ratio of the obtained fluid value and the blank value test is the scale resistance rate. The greater the remaining hardness in the water, the better the scale resistance performance, and the calculation formula is as follows:

$$
V=\frac{P_{a}-P_{0}}{P_{b}-P_{0}}
$$

Formula: $V$ : crustation inhibitor efficiency, \%;

$P_{a}$ : The volume of EDTA consumed by heating and maintaining a constant 
temperature for a certain time, $\mathrm{mL}$;

$P_{b}$ : EDTA volume consumed without scale inhibitor and without heating, $\mathrm{mL}$;

$P_{0}$ : EDTA volume consumed without scale inhibitor heating and constant temperature for a certain time, $\mathrm{mL}$;

\section{Experimental Process}

At present, most of the domestic scale resistance is mostly from water scale mechanism, by using some monomer dissolution, complex, chelation, dispersion and other chemical properties, the use of synergy between different monomers, with a variety of scale inhibitors, including carbonate, sulfate and some phosphorus-free scale resistance, etc [12]. Research can thwart stripping scale and green scale inhibitor has become the main direction of current research. This article attempts to on consulting a large number of predecessors' study of scale inhibitor in the literature, through the experiment change scale inhibitor of synthetic materials and synthetic conditions, such as looking for a new.

\subsection{Screening of the Initiator}

The initiator is an important initiator used for the polymerization reaction between monomers. In the process of product synthesis, the different addition method and dosage of the initiator will directly affect the smooth progress of the polymerization reaction process, but also affect the polymerization reaction rate, and then affect the performance of the production [13] [14]. The monomer ratio was fixed at a reaction temperature of $80^{\circ} \mathrm{C}$ and a reaction temperature of $3 \mathrm{~h}$. In the absence of the specific amount of initiator, adding the temporary dose of ammonium persulfate, potassium persulfate and sodium hydroxide, the effect of the three initiators was measured as shown in the table below.

From Table 1, after the fixed monomer ratio, the experiment found that the scale resistance efficiency of several oversulfate initiators is generally small, but because the half-life of these several initiators and the decomposition of activity ability is inconsistent, and, the market sale of potassium oversulfate price is higher, after considering the cost and effect, choose ammonium persulfate as the initiator of the experiment. The initiator was added by drip addition.

Table 1. Scale resistance effects under different initiators

\begin{tabular}{cccc}
\hline Evocating Agent & Add Way & Dosage (\%) & $\begin{array}{c}\text { Crustation Inhibitor } \\
\text { Efficiency (\%) }\end{array}$ \\
\hline Ammonium Peroxydisulfate & Dropwise & 7 & $19.37 \%$ \\
& Injection & 7 & $17.34 \%$ \\
Potassium Peroxydisulfate & Dropwise & 7 & $18.59 \%$ \\
& Injection & 7 & $16.67 \%$ \\
Sodium Peroxydisulfate & Dropwise & 7 & $18.43 \%$ \\
& Injection & 7 & $15.86 \%$
\end{tabular}




\subsection{Screening of the Monomer Ratio}

We know that the groups have different properties between the different monomers, for example, sulfonic acid group can enhance the dispersion ability to scale and not sensitive to salt, and polymerization with carboxylate can effectively improve the scale resistance and salt-resistance performance of carboxylic acid [15]. Therefore, it is determined in the monomer selection as acrylic acid, methacrylate, sodium acrylic sulfonate, and AMPS. The ratio of monomers was determined after performing the optimization experiment.

\subsubsection{Proportional Screening of Chyconic and Methacrylic Acid}

To determine the initiator as ammonium persulfate, $7 \%$ of the initiator was added at a reaction temperature of $80^{\circ} \mathrm{C}$ and a reaction time of $4 \mathrm{~h}, 5 \mathrm{~g}$ of sodium acrysulfonate, AMPS3g was added under reaction conditions to change the proportion of chlameconate and methacrylate, using the static method, and the results are shown in Table 2:

The experimental data on the table show that with the gradual increase of chycononic acid dosage after the fixed ratio of monomer, the scale resistance rate of the resulting polymer reached a maximum of $62.53 \%$. This is because the carboxylic acid group in chycononic acid is a hydrophilic group, which can chelate and lattice distortion on the barium molecule in the water, which can disperse the scale formed and destroy the crystal type of scale [16]. In the gradual increase of yconic acid, the scale resistance rate was significantly improved.

\subsubsection{Volume Screening for AMPS}

The mass ratio of fixed chycloconate, methacrylate, and sodium acrylic sulfonate was 2:1:1. With the initiator 7\%, different AMPS was added at a reaction temperature of $80^{\circ} \mathrm{C}$ and a reaction time of $4 \mathrm{~h}$, and then the scale resistance efficiency of the polymer was measured as shown in Table 3.

It can be seen from the table that with the increase of AMPS content, the scale rate did not increase significantly. From then on, it can be seen that the scale efficiency of the scale inhibitor is mainly affected by carboxylic polymerization molecules, and when AMPS is $5 \mathrm{~g}$, it is low because excessive AMPS easily leads to molecular autolpolymerization and reduces the scale rate [17], so AMPS increase is $4 \mathrm{~g}$.

Table 2. Effect of ratio on scale resistance effect.

\begin{tabular}{ccc}
\hline $\begin{array}{c}\text { Experimental } \\
\text { Serial Number }\end{array}$ & $\begin{array}{c}\text { itaconic Acid:Methacrylic Acid } \\
\text { (g:g) }\end{array}$ & $\begin{array}{c}\text { Crustation Inhibitor } \\
\text { Efficiency (\%) }\end{array}$ \\
\hline 1 & $1: 2$ & 53.47 \\
2 & $1: 1.5$ & 56.64 \\
3 & $1: 1$ & 58.96 \\
4 & $1.5: 1$ & 60.47 \\
5 & $2: 1$ & 62.53 \\
\hline
\end{tabular}


Table 3. Scale resistance effect after the addition of different AMPS.

\begin{tabular}{ccc}
\hline Experimental Sequences & AMPS (g) & Crustation Inhibitor Efficiency (\%) \\
\hline 1 & 1 & 59.74 \\
2 & 2 & 61.28 \\
3 & 3 & 63.37 \\
4 & 4 & 65.52 \\
5 & 5 & 64.23 \\
\hline
\end{tabular}

Table 4. Scale resistance effect of different sodium acrylic sulfonate plus amounts.

\begin{tabular}{ccc}
\hline Experimental Sequences & Sodium Allylsulfonate (g) & $\begin{array}{c}\text { Crustation Inhibitor Efficiency } \\
(\%)\end{array}$ \\
\hline 1 & 2 & 68.54 \\
2 & 3 & 69.16 \\
3 & 4 & 77.68 \\
4 & 5 & 73.68 \\
5 & 6 & 68.26 \\
\hline
\end{tabular}

\subsubsection{Selection of Sodium Acrylate Sulfonate}

The mass ratio of fixed cycloconate, methacrylate, and AMPS was 2:1:1. The addition to the initiator was $7 \%$. The reaction temperature was $80^{\circ} \mathrm{C}$, and after $4 \mathrm{~h}$ of full reaction, the resulting polymer scale resistance efficiency measured after adding different doses of methacrylate is shown in Table 4.

According to the data in the table, with the increase of the sodium acrylic sulfonate, the scale resistance rate also increases, reaching a maximum value of $77.68 \%$ when the sodium acrylic sulfonate is $4 \mathrm{~g}$. When added to $6 \mathrm{~g}$, the scale resistance efficiency is reduced, because the sodium acrylic sulfonate and AMPS share the sulfonate group, which reduces the scale resistance effect of the carboxylic acid molecules in excess, so the sodium acrylic sulfonate is selected as $4 \mathrm{~g}$.

\subsection{Optimization Thetic Synthesis Optimization}

In order to synthesize the scale inhibitor of the optimal conditions, in addition to finding the optimal ratio between monomer and monomer, the synthetic conditions are also one of the important reasons affecting the effect of the scale inhibitor, such as the reaction temperature, initiator dosage and reaction time in the synthesis of the scale inhibitors. After finding the appropriate monomer ratio, the orthogonal experiment is optimal to test the scale resistance rate design under different synthetic conditions.

\subsubsection{Effect of Initiator Dosage on Scale Resistance Rate}

The mass ratio of fixed itaconic acid, methacrylate, AMPS, and sodium acrylic sulfonate is $2: 1: 1: 1$, the reaction temperature is $70^{\circ} \mathrm{C}$, the reaction time is $3 \mathrm{~h}$, and the performance of scale inhibitor developed under different initiator dosage is shown 
in Table 5.

\subsubsection{Effects of Reaction Time on Scale Resistance Rate}

The mass ratio of fixed chcononic acid, methacrylate, AMPS, and sodium acrylic sulfonate was $2: 1: 1: 1$, the initiator dosage is $7 \%$ and the reaction temperature is $70^{\circ} \mathrm{C}$. The properties of the scale inhibitor developed at different reaction times are shown in Table 6.

\subsubsection{Effect of Reaction Temperature on Scale Resistance Rate}

The effect of temperature on the synthetic scale inhibitor is mainly in the polymerization speed constant of the polymer, and the mass ratio of fixed chtaconate, methacrylic acid, AMPS and sodium acrylic sulfonate is $2: 1: 1: 1$, and the selected initiator increase is $7 \%$ and the reaction time is 4 . The performance of the scale inhibitor developed at different reaction temperatures is shown in Table 7.

\subsubsection{Optimization of the Reaction Conditions}

After conducting separate experiments on the reaction conditions, the scale resistance efficiency corresponding to each separate condition was obtained. The

Table 5. Effects of initiator dosage on scale resistance effect.

\begin{tabular}{ccc}
\hline Experimental Sequences & $\begin{array}{c}\text { Increase the Amount } \\
\text { of Initiator (\%) }\end{array}$ & $\begin{array}{c}\text { Crustation Inhibitor } \\
\text { Efficiency (\%) }\end{array}$ \\
\hline 1 & 6 & 70.47 \\
2 & 7 & 79.75 \\
3 & 8 & 86.17 \\
\hline
\end{tabular}

Table 6. Effects of different reaction times on scale resistance effects.

\begin{tabular}{ccc}
\hline Experimental Sequences & Reaction Time (h) & Crustation Inhibitor Efficiency (\%) \\
\hline 1 & 2 & 76.85 \\
2 & 3 & 81.64 \\
3 & 4 & 86.37 \\
4 & 5 & 84.16 \\
\hline
\end{tabular}

Table 7. Effects of different reaction temperatures on the scale resistance effects.

\begin{tabular}{ccc}
\hline Experimental Sequences & Reaction Temperature $\left({ }^{\circ} \mathrm{C}\right)$ & $\begin{array}{c}\text { Crustation } \\
\text { Inhibitor Efficiency } \\
(\%)\end{array}$ \\
\hline 1 & 65 & 73.47 \\
2 & 70 & 79.14 \\
3 & 75 & 85.18 \\
4 & 80 & 89.64 \\
5 & 85 & 86.57 \\
6 & 90 & 84.73 \\
\hline
\end{tabular}


orthogonal experiments were arranged, by grouping the different reaction conditions, and the experimental table of orthogonal factors is shown in Table 8 below.

Orthogonal experimental groups are shown in Table 9.

Table 10 was analyzed using the extreme method. In factor A, the mean was maximum $K_{3}$, factor $B$, maximum $K_{3}$ in mean, and factor $C$, maximum $K_{3}$ in mean. Comparing the $\mathrm{R}$ values we found that $\mathrm{A}>\mathrm{B}>\mathrm{C}$. That is, the biggest impact on the scale resistance effect is the initiator plus dosage, followed by the reaction temperature, and finally is the reaction time. In conclusion, the optimal reaction conditions obtained were $A_{3} B_{3} C_{3}$. That is, the reaction time is $4 h$, the reaction temperature is $80^{\circ} \mathrm{C}$, and the initiator plus dose is $8 \%$.

Table 8. Orthogonal experimental factors.

\begin{tabular}{cccc}
\hline \multirow{2}{*}{ Factor } & A & B & C \\
& The Dosage of the Initiator (\%) & Reaction Time $(h)$ & Reaction \\
\hline 1 & 6 & 2 & 60 \\
2 & 7 & 3 & 70 \\
3 & 8 & 4 & 80 \\
\hline
\end{tabular}

Table 9. Orthogonal experimental groups of the reaction conditions.

\begin{tabular}{ccccc}
$\begin{array}{c}\text { Experimental } \\
\text { Group }\end{array}$ & $\begin{array}{c}\text { The Dosage of } \\
\text { the Initiator }\end{array}$ & $\begin{array}{c}\text { Reaction } \\
\text { Time }\end{array}$ & $\begin{array}{c}\text { Reaction } \\
\text { Temperature }\end{array}$ & $\begin{array}{c}\text { Crustation Inhibitor } \\
\text { Efficiency (\%) }\end{array}$ \\
\hline 1 & 1 & 1 & 1 & 76.78 \\
2 & 1 & 2 & 3 & 77.36 \\
3 & 1 & 3 & 2 & 80.57 \\
4 & 2 & 1 & 3 & 76.42 \\
5 & 2 & 2 & 2 & 83.16 \\
6 & 2 & 3 & 1 & 87.67 \\
7 & 3 & 1 & 2 & 90.46 \\
8 & 3 & 2 & 1 & 79.54 \\
9 & 3 & 3 & 3 & 85.45 \\
\hline
\end{tabular}

Table 10. Orthogonal results data table.

\begin{tabular}{cccc}
\hline Horizontal Value & A & B & C \\
\hline $\mathrm{K}_{1}$ & 78.24 & 81.22 & 81.33 \\
$\mathrm{~K}_{2}$ & 82.42 & 80.02 & 79.74 \\
$\mathrm{~K}_{3}$ & 85.15 & 84.56 & 84.73 \\
$\mathrm{R}$ & 6.91 & 4.54 & 4.99 \\
\hline
\end{tabular}




\section{Indoor Evaluation and Performance Analysis}

\subsection{Evaluation of Salt-Resistance Performance}

To test the salt-resistance of CQC-1, the simulated formation water was equipped with simulated saline of different mineralizations. Different concentrations of CQC1 scale inhibitor were added to $100 \mathrm{ml}$ of simulated saline and injected water, and injected water were added to an $80^{\circ} \mathrm{C}$ bath with constant temperature for $1 \mathrm{~h}$. After constant temperature, simulated saline and injected water were mixed in different volumes to test the scale retardant capacity of CQC-1 at different volumes is shown in Figure 2 below.

As can be seen from Figure 2, with the continuously increasing amount of the scale inhibitor, reaching the maximum value is $90.46 \%$ at the concentration of $60 / \mathrm{mg} \cdot \mathrm{L}^{-1}$. After allocating different concentrations of saline, we found that, although slightly decreased, the scale resistance rate remained stable above $75 \%$ at the concentration of $60 / \mathrm{mg} \cdot \mathrm{L}^{-1}$, which shows that the scale inhibitor CQC-1 has excellent salt-resistance, because the sulfonate group was added to the polymerization process, and the sulfonate group has good temperature and salt-resistance performance.

\subsection{Biodegradability Analysis}

The biodegradability of the scale inhibitor CQC-1 was assessed by standard dilution [18], and observed once a week at room temperature of $20^{\circ} \mathrm{C} \pm 1^{\circ} \mathrm{C}$, and data testing the scale inhibitor and other commercially available are shown in Figure 3.

As can be seen from the figure, both PSPA and CQC-1 are easily biodegradable categories, with the biodegradation rate both reached more than $60 \%$ within $28 \mathrm{~d}$, and CQC-1 reached more than 70\%, with excellent biodegradation performance. Although the sulfonic acid group in the monomer interferes with the polymerization of the enzyme, the degradation process can proceed as always

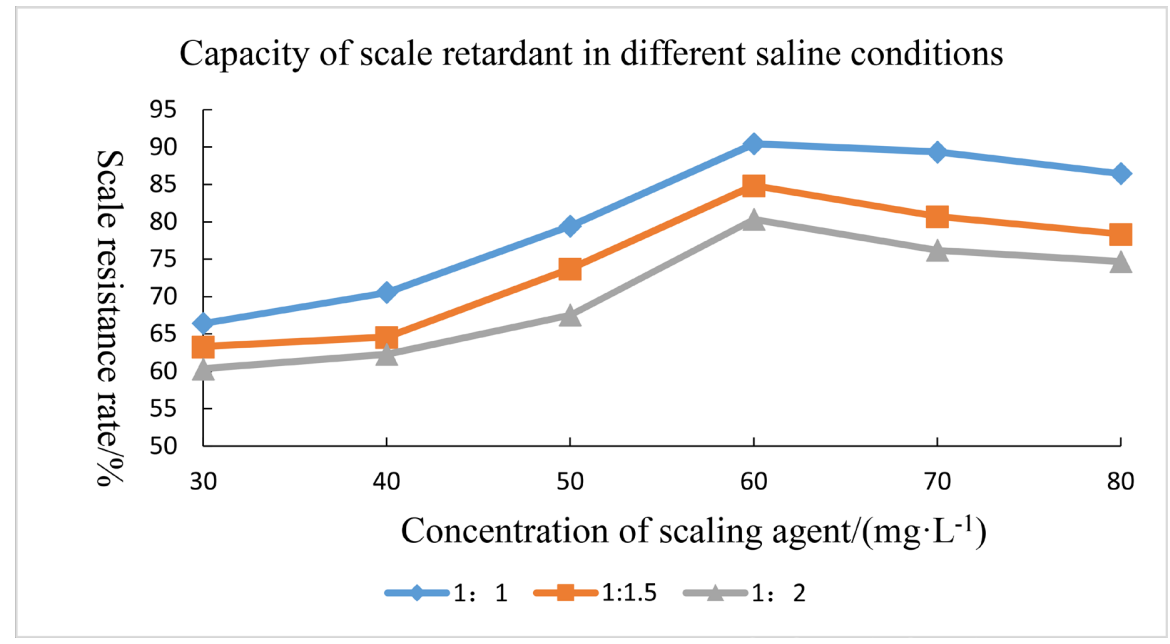

Figure 2. Capacity of scale retardant under different proportions of saline. 


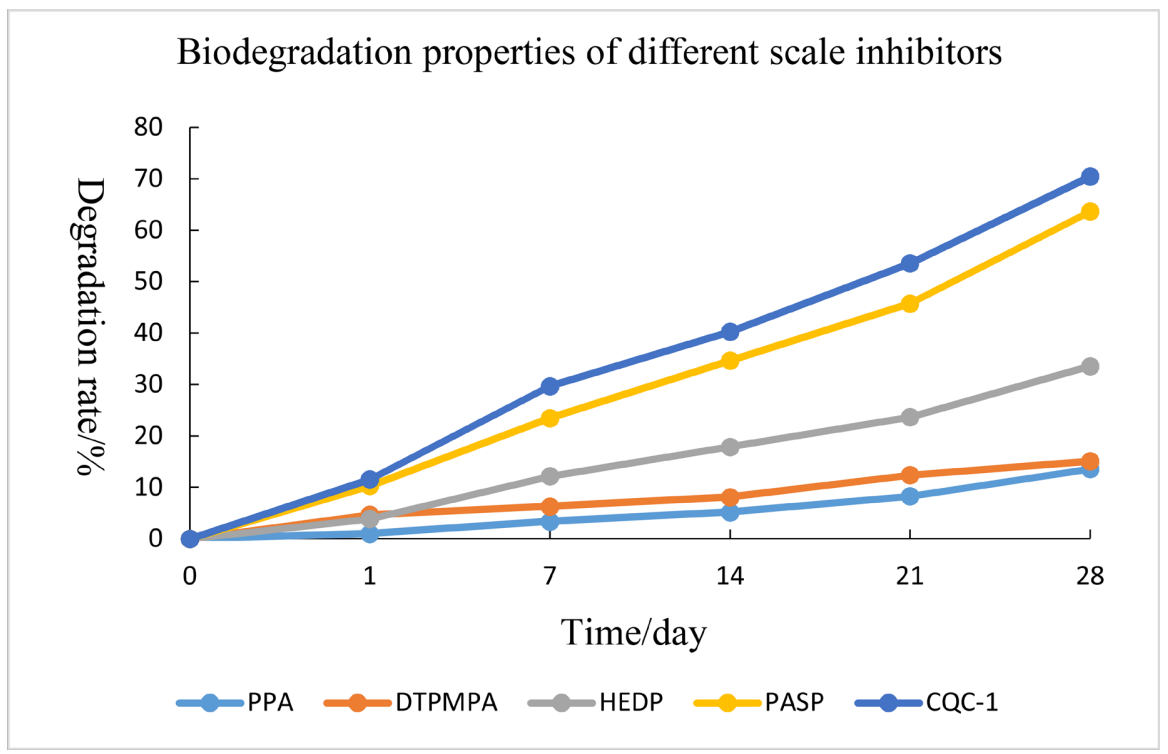

Figure 3. Biodegradation curve of the scale inhibitor.

due to the promoting degradation of the carboxylate group in the added chyconic acid.

\subsection{Thermal Stability Evaluation}

Temperature resistance performance is one of the very important properties of scale retardant. Due to the complexity of underground operation, if the temperature resistance performance of scale resistance agent is too poor, it is easy to lead to the unstable chemical nature of the product and lose the original effect. The scale-resistant agent CQC-1 was prepared into a $1 \%$ concentration of aqueous solution with deionized water. The following step is, place the configured aqueous solution in the beaker into the magnetic mixer, test the temperature resistance performance of the scale inhibitor in $100^{\circ} \mathrm{C}-160^{\circ} \mathrm{C}$ respectively, and observe the solution status and scale resistance performance as shown in Table 11.

According to Table 11, in the process of increasing the temperature between $100^{\circ} \mathrm{C}$ and $150^{\circ} \mathrm{C}$, it tends to be stable, but when the temperature rises to $160^{\circ} \mathrm{C}$, the scale resistance rate dropped sharply from $80.65 \%$ to $73.16 \%$.The solution state solution began to become slightly cloudy, producing small particles. It is proved that the scale inhibitor is stable at a high temperature of $150^{\circ} \mathrm{C}$.

\subsection{Comparison of Scale Resistance Ratio}

After a series of experiments, the maximum scale resistance efficiency of the synthetic scale inhibitor reached $90.46 \%$. In order to know whether this scale inhibitor is of value, which is one of the commercial-scale retardant agents, therefore, the commercial-scale retardant agents GYTD, AGEC and PIMA were selected. Comprehensive evaluation of CQC-1 scale inhibitor on the effect of sulfate scale at different concentrations is shown in Figure 4. 
Table 11. Temperature resistance experiment of scale inhibitor.

\begin{tabular}{|c|c|c|c|}
\hline $\begin{array}{l}\text { Experimental } \\
\text { group }\end{array}$ & $\begin{array}{c}\text { Temperature } \\
{ }^{\circ} \mathrm{C}\end{array}$ & Solution state & $\begin{array}{l}\text { Crustation inhibitor } \\
\text { efficiency (\%) }\end{array}$ \\
\hline 1 & 100 & $\begin{array}{c}\text { The solution is transparent and } \\
\text { stable without turbidity }\end{array}$ & 89.37 \\
\hline 2 & 110 & $\begin{array}{c}\text { The solution is transparent and } \\
\text { stable without turbidity }\end{array}$ & 88.74 \\
\hline 3 & 120 & $\begin{array}{c}\text { The solution is transparent and } \\
\text { stable without turbidity }\end{array}$ & 86.03 \\
\hline 4 & 130 & $\begin{array}{c}\text { The solution is transparent and } \\
\text { stable without turbidity }\end{array}$ & 85.73 \\
\hline 5 & 140 & $\begin{array}{c}\text { The solution is transparent and } \\
\text { stable without turbidity }\end{array}$ & 85.17 \\
\hline 6 & 150 & $\begin{array}{c}\text { The solution is transparent and } \\
\text { stable without turbidity }\end{array}$ & 80.65 \\
\hline 7 & 160 & $\begin{array}{c}\text { The solution appeared granular } \\
\text { and slightly cloudy }\end{array}$ & 73.16 \\
\hline
\end{tabular}

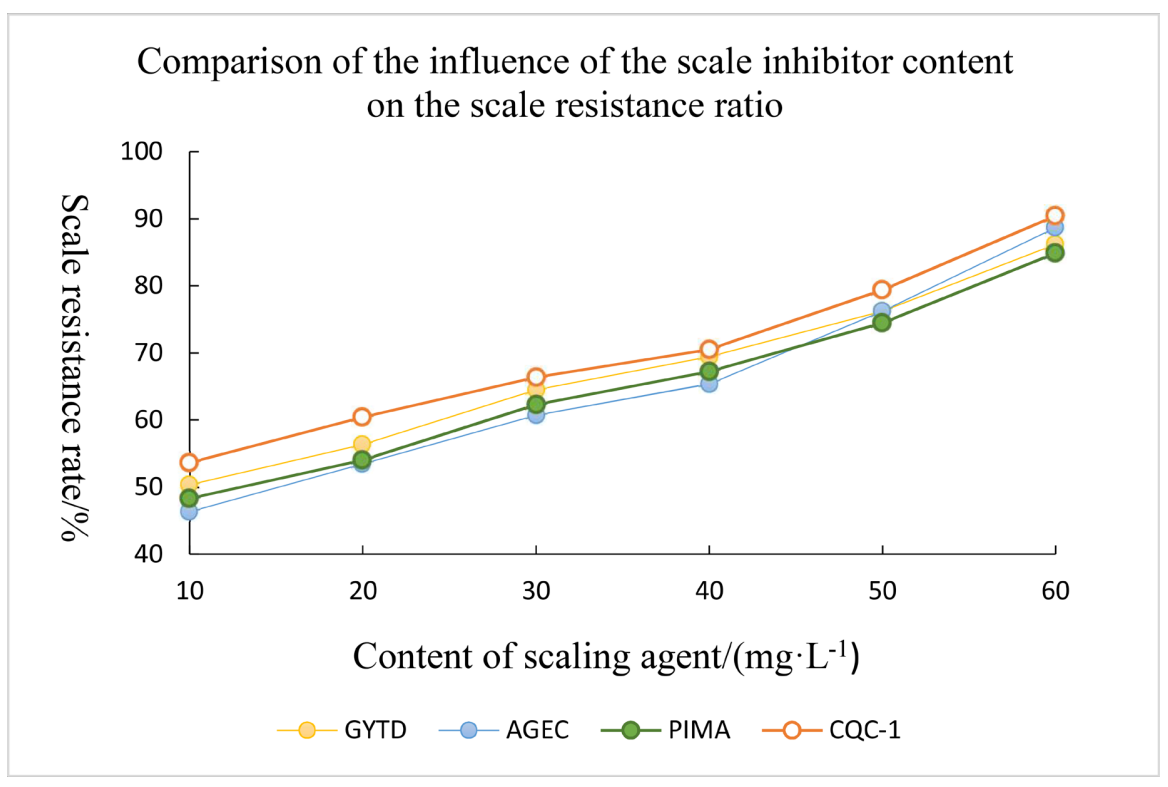

Figure 4. Scale resistance capacity of different scale inhibitors.

As can be seen from Figure 4, these scale inhibitors have excellent scale retardant ability. With the increasing concentration of the scale inhibitor, the scale retardant effect is also increasing. When the concentration is $60 / \mathrm{mg} \cdot \mathrm{L}^{-1}$, the four scale inhibitors have all reached more than $80 \%$, and the CQC-1 scale inhibitor has reached $90.46 \%$, with excellent scale retardant effect.

\section{Conclusions}

The optimal formulation and reaction conditions of synthetic scale inhibitors are: 
the mass ratio of conate:methacrylic:AMPS:sodium acrylic sulfonate is $2: 1: 1: 1$, the initiator is $8 \%$ of the monomer amount, the reaction time is $4 \mathrm{~h}$, and the reaction temperature is $80^{\circ} \mathrm{C}$. The scale inhibitor CQC- 1 is $90.46 \%$, which still reaches $80.65 \%$ at $150^{\circ} \mathrm{C}$, has stable chemical properties, and reaches $70.5 \%$ within $28 \mathrm{~d}$, which is a easily biodegradable product. It has an excellent performance, with good development potential of sulfate scale inhibitor.

Using the way of aqueous solution polymerization, in addition of initiator selection drops, the synthetic scale inhibitor effect is excellent compared with directly filling the full dose of initiator performance. It is recommended to use the drip-adding method to synthesize scale inhibitors. Ammonium persulfate was selected in the initiator, which was added by $2.03 \%$ higher than the scale resistance effect at filling. Therefore, it is very necessary to choose the appropriate initiation mode and initiator when synthesizing scale inhibitors.

\section{Conflicts of Interest}

The authors declare no conflicts of interest regarding the publication of this paper.

\section{References}

[1] Liu, X., Zhang, H., Liu, Y., et al. (2021) Progress of the Properties and Mechanism of Scale Resistance Agent. Material Protection, 54, 150-157.

[2] Hao, Y. and Chen, X. (2020) Introduction of Mechanism of Scale Inhibitor. Chemical Engineer, 34, 58-61.

[3] Mazumder, M.A.J. (2020) A Review of Green Scale Inhibitors: Process, Types, Mechanism and Properties. Coatings, 10, Article No. 928. https://doi.org/10.3390/coatings10100928

[4] Zhang, Q. and Lai, C. (2020) Progress in the Mechanism of Action of Scale Inhibitor. Journal of Sichuan University of Arts and Sciences, 30, 18-23.

[5] Wang, H., Zhong, X. and Hu, J. (2021) Scale Resistance Rules and Mechanism of Tetraplex Copolymer Scale Inhibitor of Maleate Anhydride. Petroleum Journal (Petroleum Processing), 37, 1120-1128.

[6] Zhang, H., Wei, L., Zhou, N., et al. (2021) IA-HPA-AMPS Synthesis and Its Properties of Ternary Polymers. New Technology and New Process, 61-66.

[7] Ren, D., Zhuang, M., Zhang, S., et al. (2021) Progress in Green Scale Inhibitors. Industrial Water Treatment, 1-8.

[8] Li, H., Wang, M., Tang, H., et al. (2019) Preparation and Performance Evaluation of Barium Sulfate Scale Retardant. Journal of Xi an Petroleum University (Natural Science Edition), 34, 89-94.

[9] Rafael, S.F., Wanessa, D.L.S., de Lima Djalan, F., de Souza Miguel Angelo, F., Bruno, B.C. and Rosangela, C.B. (2021) Application of Water-Soluble Polymers as Calcium Carbonate Scale Inhibitors in Petroleum Wells: A Uni- and Multivariate Approach. Desalination, 515, Article ID: 115201. https://doi.org/10.1016/j.desal.2021.115201

[10] Pan, D., Chen, K., Feng, P., et al. (2021) Synthesis and Scale Resistance Mechanism of Barium Sulfate Scale Inhibitor PA-Q1. Contemporary Chemical Industry, 50, 873-876.

[11] Wang, Y., Li, C., Gu, L., et al. (2018) Progress in Its Research Mechanism and Per- 
formance Evaluation Method. Guangdong Chemical Industry, 45, 192-193.

[12] Yu, R., Zhou, X., Su, L., et al. (2018) Progress in Its Research Mechanism and Performance Evaluation Method. Guangdong Chemical Industry, 45, 192-193.

[13] Li, J., Tang, M.J., Zhang, L., et al. (2015) Synthesis of Barium Sulfate Scale Inhibitor and Its Properties. Petrochemical Industry, 44, 1492-1498.

[14] Gu, Y. (2017) Development and Performance Evaluation of New Barium Sulphate Scale Inhibitor. Thesis, Southwestern Petroleum University, Chengdu.

[15] Zhang, X. and Tang, M.J. (2019) Application of Sulfate Scale Inhibitor in Oil Field Development. Sichuan Chemical Industry, 22, 10-13+28.

[16] Li, C., Zhang, C. and Zhang, W. (2019) The Inhibition Effect Mechanisms of Four Scale Inhibitors on the Formation and Crystal Growth of $\mathrm{CaCO}_{3}$ in Solution. Scientific Reports, 9, Article No. 13366. https://doi.org/10.1038/s41598-019-50012-7

[17] Zhang, X. (2007) Synthesis and Application Properties of Barium Sulfate (Strontium) Scale Retardant Agent. Thesis, Southwestern Petroleum University, Chengdu.

[18] Sun, J. (2021) Measurement of BOD_5 in Water Samples. Groundwater, 43, 106-107. 